\title{
HER4 tumor expression in breast cancer patients randomized to treatment with or without tamoxifen
}

\author{
ANNA GÖTHLIN EREMO ${ }^{1}$, ELISABET TINA ${ }^{2}$, PIA WEGMAN ${ }^{3}$, OLLE STÅL $^{4}$, \\ KARIN FRANSÉN ${ }^{1}$, TOMMY FORNANDER ${ }^{5,6}$ and STEN WINGREN ${ }^{1}$
}

\author{
${ }^{1}$ Faculty of Medicine and Health, School of Health and Medical Sciences, Örebro University, SE-701 82 Örebro; \\ ${ }^{2}$ Clinical Research Centre, Örebro University Hospital, SE-701 85 Örebro; ${ }^{3}$ Department of Clinical Genetics, \\ University Hospital; ${ }^{4}$ Department of Clinical and Experimental Medicine and Department of Oncology, \\ Linköping University, SE-581 85 Linköping; ${ }^{5}$ Department of Oncology, Karolinska University Hospital, \\ Karolinska Institute, SE-171 76 Stockholm; ${ }^{6}$ Regional Cancer Center Stockholm-Gotland, SE-102 39 Stockholm, Sweden
}

Received April 15, 2015; Accepted May 25, 2015

DOI: 10.3892/ijo.2015.3108

\begin{abstract}
The human epidermal growth factor receptor (HER) 4 is a relative of HER2 and has been associated to endocrine breast cancer and prediction of tamoxifen response. In addition to PI3K/Akt and MAPK pathway activation, ligand binding to HER4 triggers proteolytic cleavage and release of an intracellular receptor domain (4ICD) with signaling properties. The aim of the present study was to analyze HER4 protein expression and intracellular localization in breast cancer tissue from patients randomized to treatment with or without adjuvant tamoxifen. To investigate HER4 expression and localization in response to estradiol (E2) and 4-hydroxytamoxifen (4-OHT) exposure, we also performed in vitro studies. Cytoplasmic, nuclear and membrane expression of HER4 protein was evaluated by immunohistochemical staining in tumor tissue from 912 breast cancer patients. Three different breast epithelia cancer cell lines were exposed to E2 and 4-OHT and mRNA expression was analyzed using qPCR. Further, nuclear and cytoplasmic proteins were separated and analyzed with western blotting. We found an association between nuclear HER4 protein expression and ER-positivity $(\mathrm{P}=0.004)$. Furthermore, significant association was found between cytoplasmic HER4 and ER-negativity $(\mathrm{P}<0.0005)$, PgR-negativity $(\mathrm{P}<0.0005)$, tumor size $>20 \mathrm{~mm}(\mathrm{P}=0.001)$ and HER2-negativity $(\mathrm{P}=0.008)$. However, no overall significance of HER4 on recurrence-free survival was found. After E2 exposure, HER4 mRNA and protein expression had decreased in two cell lines in vitro yet no changes in nuclear or cytoplasmic protein fractions were seen. In conclusion, nuclear
\end{abstract}

Correspondence to: Dr Anna Göthlin Eremo, Research Department Campus USÖ, Örebro University, SE-701 82 Örebro, Sweden

E-mail: anna.gothlin-eremo@oru.se

Key words: breast cancer, ErbB4, HER4, randomized patients, tamoxifen
HER4 seem to be co-located with ER, however, we did not find support for overall HER4 expression in independently predicting response of tamoxifen treatment. The possible influence of separate isoforms was not tested and future studies may further evaluate HER4 significance.

\section{Introduction}

Breast cancer is the largest group of malignancies among women in the Western world (1) and the majority of breast tumors express estrogen receptors (ER) (2). A common treatment strategy for these patients is blocking estrogen action by tamoxifen (2-4). One of the cellular responses of the ER block is cell cycle arrest in the G1 phase by decreased expression of the cell cycle regulator cyclin D1 (5). Tamoxifen treatment is not efficient for all patients and many experience breast cancer relapse. Endocrine drug resistance may be caused by several mechanisms, such as elevated levels of co-activating proteins involved in ER signaling or changes in tamoxifen metabolism (6-10). Despite extensive research for proteins involved in tamoxifen resistance, no breakthrough of markers has been implicated for clinical practice.

The biological significance of the human epidermal growth factor receptor (HER) 4 is not fully elucidated although it has been associated with ER expression $(11,12)$ and favorable outcome of breast cancer $(7,13)$. Like in other receptor tyrosine kinases, activation results in downstream signaling through pathways such as phosphoinositide 3-kinase (PI3K)/Akt -and Ras/mitogen activated protein kinase (MAPK) (14). There are at least four known isoforms of HER4, due to alternative splicing, having either juxtamembrane domain JM-a or JM-b (15) connected to the cytoplasmic domains CYT-1 or CYT-2 (16). These isoforms give rise to opposing effects in mammary epithelia, making it challenging to evaluate the clinical relevance $(17,18)$. Isoforms with the cleavable JM-a domain release an $80-\mathrm{kDa}$ intracellular region $(4 \mathrm{ICD} / \mathrm{s} 80)$ into the cytoplasm where it remains or is transported to the nucleus (19). The occurrence of 4ICD in the cytoplasm has been associated to apoptosis, initiated by its proapoptotic BH3-only domain 
(20-22) while nuclear 4ICD acts as a co-activator for ER $\alpha$ stimulated gene expression (23) and may therefore promote proliferation of ER-positive cells. At least one cleavable HER4 isoform (JM-a/CYT-2), shown to increase cyclin D1 in breast epithelium, cause hyperplasia in mammary epithelia (17). According to current knowledge some isoforms of HER4 may reverse the effect of tamoxifen thus decreasing patient survival while on the other hand it is also hypothesized that tamoxifen disrupts the ER $\alpha / 4 \mathrm{ICD}$ complex in tumor cells by mitochondrial accumulation of 4ICD and subsequent apoptosis (20). In the present study we evaluated the expression and localization of HER4 using immunohistochemistry and the association to prognosis and clinical parameters in 912 breast cancer patients randomized to tamoxifen or to no endocrine treatment. We also examined the effect of estrogen ( $\beta$-estradiol, E2) and tamoxifen (4-hydroxy-tamoxifen, 4-OHT) on HER4 cellular localization in vitro.

\section{Materials and methods}

Patients. We analyzed tissue from low risk breast cancer patients registered in a randomized tamoxifen trial, conducted in the Stockholm region between 1976 and 1990. This cohort has been described in detail elsewhere (24). All patients $(n=1,780)$ were female and postmenopausal at the time of diagnosis. For inclusion, they were required to have a tumor $\leq 30 \mathrm{~mm}$ with no infiltrating tumor cells in axillary lymph nodes (N0). The patients were treated either with modified radical mastectomy or with breast conserving surgery plus radiation therapy (50 Gy/5 weeks). Patients were randomized to tamoxifen therapy ( $40 \mathrm{mg} / \mathrm{day})$ for 2 years $(\mathrm{n}=886)$ or no adjuvant endocrine treatment $(n=894)$. Tamoxifen treatment was initiated within 2-4 weeks after surgery thus administered concurrently with radiation therapy. Patients without recurrence after 2 years were re-randomized to additional 3 years of tamoxifen therapy, hence a total treatment period of 5 years, or no further treatment. The mean follow-up period was 17 years and the patient data were collected through regional population registers including Swedish Cause of Death Registry. The study was approved by the ethics committee at the Karolinska Institute and the experiments in the present study were conducted according to the Declaration of Helsinki.

Breast cancer tissue microarray. Archival breast tumor tissue from 912 of the 1,780 patients participating in the original study were collected. A pathologist chose representative tissue from formalin-fixed, paraffin-embedded breast tumor material as donor block for tissue microarray (TMA). From each block a section was stained with hematoxylin and eosin. Further, three morphologically representative regions from each section were chosen and then cylindrical cores with a diameter of $0.8 \mathrm{~mm}$ were taken and mounted in a recipient block. For each TMA, cores from liver tissue were mounted as internal controls. The TMA were constructed using a manual arrayer (Beecher Instruments, Sun Prairie, WI, USA).

Hormone receptor status and HER2. The tumor data of hormone receptors and HER2 was obtained from prior studies. In brief, ER status was initially determined by cytosol assay and isoelectric focusing with a cut-off level set to $0.05 \mathrm{fmol} / \mu \mathrm{g}$
DNA, according to earlier clinical routine practice (24). In the present study, ER data were collected from a re-evaluation using immunohistochemistry (IHC). Briefly, the Ventana Benchmark system with prediluted antibodies (anti-ER clone 6F11 and anti-PgR clone 16) was used to determine the ER and progesterone $(\mathrm{PgR})$ status. Tumors with $>10 \%$ positively stained nuclei were considered positive. For cases without immunohistochemical data, results from cytosolic assay were used. Expression of HER2 was analyzed using the Dako AO0485 polyclonal rabbit antibody (Dako, Glostrup, Denmark). The tumor cells were graded $(0,1+, 2+$ and $3+)$ and patients having a score of $3+$ were considered HER2-positive.

HER4 analysis. IHC specific monoclonal rabbit anti-HER4 antibody \#4792 (Cell Signaling Technology Inc, Beverly, MA, USA) was used at dilution of 1:350. According to suppliers, the antibodies do not cross-react with other EGFR family members. The specificity of the antibody was evaluated by pre-incubation with a blocking peptide \#1022 (Cell Signaling Technology Inc.) for $1 \mathrm{~h}$ in room temperature (RT) prior incubation of tissue (Fig. 1). In addition, the antibody was successfully tested using tissue with known HER4 expression and western blotting. The TMA slides were deparaffinized in xylene and rehydrated in decreasing series of ethanol followed by MilliQ water. Heat-induced antigen retrieval was performed in Target Retrieval Solution pH 9.0 (Dako) for $1 \mathrm{~h}$ in a $99^{\circ} \mathrm{C}$ water bath and then cooled to RT. The slides were blocked for endogenous peroxidase activity using $3 \% \mathrm{H}_{2} \mathrm{O}_{2}$ for 10 min following $1 \mathrm{~h}$ treatment in RT with $5 \%$ horse serum diluted in phosphatebuffered saline (PBS). The slides were incubated with primary antibody at $4^{\circ} \mathrm{C}$ overnight, washed and forthcoming detection was made using the EnVision ${ }^{\mathrm{TM}}$ system (Dako) with secondary horseradish peroxidase (HRP) polymer reagent for $20 \mathrm{~min}$ at RT and subsequently visualized with 3,3'-diaminobenzidine (DAB). Sections were counterstained with hematoxylin and mounted. All washing between reactions was performed using PBS with $0.1 \%$ Tween.

TMA evaluation. The TMA slides were examined in Olympus BX41 light microscope (Olympus Life Science Europe GMBH, Hamburg, Germany) connected to Leica DFC420 digital microscope camera (Leica Microsystems, Heerbrugg, Switzerland). Two investigators (A. Göthlin Eremo and P. Wegman) evaluated the slides independently and unaware of clinical data and patients outcome, by grading the staining intensity of cytoplasmic and nuclear HER4 (0, negative; 1 , weak/moderate; 2 , strong). The cut-off level for a positive signal was set at $>10 \%$ of tumor cells. If results were not consistent between investigators, a consensus score was set after re-evaluation.

Cell culture and reagents. To investigate HER4 intracellular response from estrogen and tamoxifen exposure, three epithelial breast cancer cell lines were used; MCF7, ZR-75-1 and T-47D (American Type Culture Collection, Manassas, VA, USA). All three cell lines are considered ER-positive and in addition, ZR-75-1 cells also express low levels of HER2 (25). MCF7 cells were cultured in Iscove's modified Dulbecco's medium (IMDM) complemented with $10 \% \mathrm{FBS}$ and $0.25 \%$ insulin. ZR-75-1 cells were cultured in RPMI-1640 supplemented with 

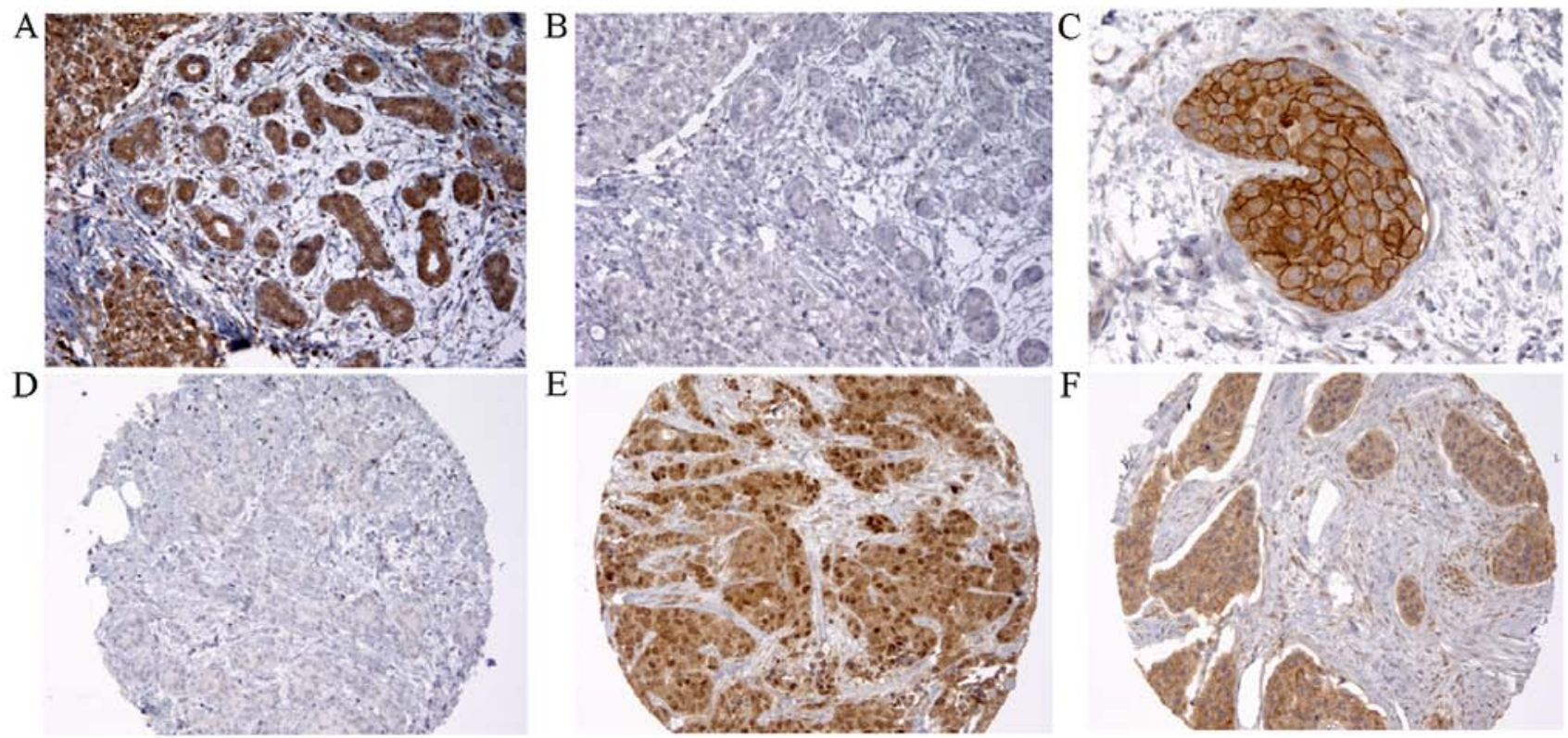

Figure 1. Micrographs of HER4 staining pattern in breast cancer (x20 magnification). (A) A HER4-positive breast cancer specimen incubated with anti-HER4 antibody concurrent with a peptide corresponding to the epitope to which the antibody was raised. (B) The same breast cancer specimen was incubated with anti-HER4 antibody alone. (C) An island of tumor cells having membranous HER4 staining (x40 magnification). (D) Micrograph of a tumor specimen considered HER4-negative (HER4 ${ }^{-}$). (E) Nuclear and cytoplasmic HER4 (HER4 ${ }^{\mathrm{NC}}$ ). (F) A tumor showing exclusively cytoplasmic staining (HER4 ${ }^{\mathrm{C}}$ ).

$10 \%$ FBS and $2.5 \%$ HEPES buffer. T-47D cells were grown in in RPMI-1640 supplemented with $10 \%$ FBS, $2.5 \%$ HEPES buffer and $0.25 \%$ insulin. All cell culture media were free from phenol red. In between experiments, cells were incubated in $75-\mathrm{cm}^{2}$ culture flasks in a $5 \% \mathrm{CO}_{2}$ humidified atmosphere at $37^{\circ} \mathrm{C}$. Cell culture media and supplements were purchased from Invitrogen, Carlsbad, CA, USA.

In vitro experiments. For cell experiments, the use of conventional FBS was changed to 5\% charcoal stripped FBS (csFBS) (Invitrogen) to avoid influence from unknown concentrations of steroid hormone. Culture conditions and drug concentrations were optimized prior to experiments. The cells were seeded at a density of 20,000 cells $/ \mathrm{cm}^{2}$ in 6 -well plates and cultured for $24 \mathrm{~h}$. Cells were then exposed for $72 \mathrm{~h}$ to either 100 nM 4-hydroxytamoxifen (4-OHT) (Sigma-Aldrich, Stockholm, Sweden), $1 \mathrm{nM} \beta$-estradiol (E2) (Sigma-Aldrich), or both 4-OHT and E2 in combination. E2 and 4-OHT were dissolved using ethanol (EtOH), hence control cells were cultured in $0.1 \%$ EtOH. After exposure, cells were harvested by trypsinization, using $0.5 \%$ trypsin/EDTA, and centrifuged at $300 \mathrm{x} \mathrm{g}$ for $5 \mathrm{~min}$ for following procedures.

Analysis of HER4 and cyclin D1 expression using quantitative real-time PCR ( $q P C R)$. RNA was extracted, using the RNeasy Plus Micro kit (Qiagen, Hilden, Germany) according to the manufacturer's protocol. RNA concentrations were determined using the NanoDrop Spectrophotometer ND-1000 (NanoDrop Technologies; Thermo Fisher Scientific, Wilmington, DE, USA) and stored at $-80^{\circ} \mathrm{C}$ until further use. Later, samples were thawed and diluted with RNase-free water. A total of $400 \mathrm{ng}$ RNA was reverse transcribed in a $20-\mu 1$ reaction using the High Capacity cDNA RT kit (Applied Biosystems, Foster City, CA, USA), according to the manufacturer's protocol. The cDNA was synthesized in following conditions; $25^{\circ} \mathrm{C}$ for $10 \mathrm{~min}, 37^{\circ} \mathrm{C}$ for $120 \mathrm{~min}, 85^{\circ} \mathrm{C}$ for $5 \mathrm{~min}$ and cooled to $4^{\circ} \mathrm{C}$ by using the $\mathrm{MJ}$ Research PTC-200 Peltier Thermal Cycler (GMI Inc., Ramsey, MI, USA). qPCR was carried out in a solution containing $7.5 \mu \mathrm{l}(2 \mathrm{X}) \mathrm{TaqMan}^{\circledR}$ Fast Advanced PCR Master Mix (Applied Biosystems), $0.75 \mu \mathrm{l}$ (20X) TaqMan Gene Expression Assays (Applied Biosystems) (HER4: Hs00955525_m1, cyclin D1; Hs00765553_m1, $\beta$-actin; Hs99999903_m1, ABL1; Hs01104728_m1), $6 \mu$ l RNase-free $\mathrm{H}_{2} \mathrm{O}$ and $1.5 \mu \mathrm{l}$ cDNA with the final volume of $15 \mu \mathrm{l}$. The 96 -well plates were run, using the C1000 Touch $^{\mathrm{TM}}$ Thermal Cycler (CFX96 ${ }^{\mathrm{TM}}$ Real-Time System, Bio-Rad, Solna, Sweden) in $50^{\circ} \mathrm{C}$ for $2 \mathrm{~min}, 95^{\circ} \mathrm{C}$ for $20 \mathrm{sec}$ and $95^{\circ} \mathrm{C}$ for $1 \mathrm{sec}$ and $60^{\circ} \mathrm{C}$ for $20 \mathrm{sec}$ for 40 cycles. The fold change between expression of the target genes (HER4 and cyclin D1) and house-keeping genes ( $\beta$-actin and ABL1) was obtained using the $2^{-\Delta \Delta C t}$ method.

Separation of nuclear and cytoplasmic proteins. In order to analyze HER4 localization in response of E2 and 4-OHT exposure, nuclear and cytoplasmic proteins were isolated. Briefly, the cells were re-suspended in $1.5 \mathrm{ml}$ PBS and centrifuged at $500 \mathrm{x}$ g for $5 \mathrm{~min}\left(4^{\circ} \mathrm{C}\right)$. The proteins were extracted and separated through a series of centrifugation steps using NE-PER ${ }^{\circledR}$ Nuclear and Cytoplasmic Extraction reagents (Thermo Scientific, Rockford, IL, USA) according to the manufacturer's protocol. Before use, $10 \mu \mathrm{l} / \mathrm{ml}$ of Protease Inhibitor Cocktail (Sigma-Aldrich) was added to reagent CER I and NER. Protein concentrations were determined by spectrophotometry using DC Protein Assay (Bio-Rad) and 96-well plate reader Multiskan Ascent (Thermo Labsystems, Helsinki, Finland) according to instructions.

Western blot analysis of HER4 and cyclin D1 protein expression. From the nuclear and cytoplasmic cell fractions, $40 \mu \mathrm{g}$ 
Table I. Comparison of the distribution of characteristics for included patients with tumor tissue on TMA, patients with tumors assessed for HER4 protein expression and the patients from the original cohort. ${ }^{a}$

\begin{tabular}{|c|c|c|c|c|}
\hline & \multicolumn{4}{|c|}{ No. of patients $(\%)$} \\
\hline & $\begin{array}{l}\text { Patients in present } \\
\text { study }(\mathrm{n}=912)\end{array}$ & $\begin{array}{l}\text { Patients assessed for HER4 } \\
\text { expression }(n=727)\end{array}$ & $\begin{array}{l}\text { Original randomized } \\
\text { study }(\mathrm{n}=1,780)\end{array}$ & P-value ${ }^{b}$ \\
\hline \multicolumn{5}{|c|}{ Estrogen receptor } \\
\hline Positive & $684(77)$ & $544(77)$ & $1,183(80)$ & 0.18 \\
\hline Negative & $200(23)$ & $162(23)$ & $296(20)$ & \\
\hline Unavailable & 28 & 21 & & 301 \\
\hline \multicolumn{5}{|c|}{ Progesterone receptor } \\
\hline Positive & $379(48)$ & $306(47)$ & $590(48)$ & 0.86 \\
\hline Negative & $416(52)$ & $342(53)$ & $627(52)$ & \\
\hline Unavailable & 117 & 79 & 563 & \\
\hline \multicolumn{5}{|c|}{ Tumor diameter } \\
\hline$\leq 20 \mathrm{~mm}$ & $697(79)$ & $552(78)$ & $1,393(81)$ & 0.09 \\
\hline$>20 \mathrm{~mm}$ & $189(21)$ & $159(22)$ & 323 (19) & \\
\hline Unavailable & 26 & 16 & 64 & \\
\hline \multicolumn{5}{|c|}{ Tamoxifen treatment } \\
\hline Yes & $473(52)$ & $369(51)$ & $886(50)$ & 0.59 \\
\hline No & $439(48)$ & 358 (49) & $894(50)$ & \\
\hline
\end{tabular}

${ }^{\mathrm{a} A s}$ shown, the distribution of characteristics for patients in the present study cohort ( $\left.\mathrm{n}=912\right)$ do not differ from those with available HER4-scoring. bP-values were calculated with Chi-square test.

of proteins were separated by SDS-PAGE using Any $\mathrm{kD}^{\mathrm{TM}}$ Mini-PROTEAN ${ }^{\circledR}$ TGX $^{\text {TM }}$ Precast Gel (Bio-Rad) and subsequently transferred to Immun-blot ${ }^{\mathrm{TM}}$ PVDF (Bio-Rad) membranes. The membranes were blocked for unspecific binding for $1 \mathrm{~h}$ at RT using 2\% ECL Advance Blocking Agent (GE Healthcare, Buckinghamshire, UK) then incubated with rabbit monoclonal anti-HER4 antibody \#4795 (Cell Signaling) $(1: 1,000)$ at $4{ }^{\circ} \mathrm{C}$ overnight. For detection, the membranes were incubated with goat anti-rabbit HRP conjugated antibody \#AS09 602 (Agrisera, Vännäs, Sweden) $(1: 50,000)$ for $1 \mathrm{~h}$ at RT and visualized using the ECL Advance Western Blotting Detection kit (GE Healthcare) and ChemiDoc charge-coupled device (CCD) camera (Bio-Rad) according to the manufacturer's instructions. Antibodies were stripped off the membrane by stripping buffer (0.1 M $\beta$-mercaptoethanol, $2 \%$ SDS, $62.5 \mathrm{mM}$ Tris, $\mathrm{pH}$ 6.7) incubation at $50^{\circ} \mathrm{C}$ for $30 \mathrm{~min}$. From the step of blocking, the protocol was repeated using rabbit monoclonal anti-cyclin D1 antibody \#2978 (Cell Signaling) $(1: 1,000)$, rabbit polyclonal anti- $\beta$ actin antibody \#ab8227 (Abcam, Cambridge, UK) $(1: 2,500)$ and finally rabbit monoclonal anti-histone H3 antibody \#9717 (Cell Signaling) $(1: 1,000)$ for $1 \mathrm{~h}$ at RT.

Statistical analysis. To examine the relationship between the levels of protein expression and tumor characteristics the Pearson's Chi-square test was used. The differences in recurrence-free survival were assessed using the log-rank test. Hazard ratios (relative hazard, HR) with $95 \%$ confidence interval (95\% CI), were calculated using univariate and multivariate Cox proportional hazards regression analysis, which was also used for interaction tests. In addition, the fold changes in gene expression from qPCR results were estimated using the $2^{-\Delta \Delta \mathrm{Ct}}$ method and the differences $(\Delta \mathrm{Ct})$ were tested using one-way ANOVA with Holm-Sidak test for correction of multiple comparisons. All P-values $\leq 0.05$ were considered significant. The Statistical Package for the Social Sciences (SPSS) version 17.0 and GraphPad Prism version 6.0d were used to perform the statistical analyses.

\section{Results}

HER4 protein expression and localization. Protein expression of HER4 was assessed in tumor tissue from 912 breast cancer patients and scoring was attainable in 727 cases $(79.7 \%)$. The distributions of tumor characteristics for these cases were similar to those available on TMA and to the original cohort (Table I). For accessible cases, nuclear and cytoplasmic HER4 were evaluated separately and graded (Table II). Tissues with moderate and strong grade of immunoreactivity were considered HER4-positive $\left(\mathrm{HER}_{4}{ }^{+}\right)$. Two hundred and thirty-five $(32.3 \%)$ tumors were considered as HER4-negative (HER4), 28 (3.9\%) had exclusively nuclear staining $\left(\mathrm{HER}^{\mathrm{N}}\right.$ ) and $388(53.4 \%)$ had only cytoplasmic staining (HER4 ${ }^{\mathrm{C}}$ ). Seventy-six patients (10.5\%) had both nuclear and cytoplasmic HER4 (HER4 ${ }^{\mathrm{NC}}$ ) and for 70 cases $(9.6 \%)$, a distinct membranous staining was found (Table II). 


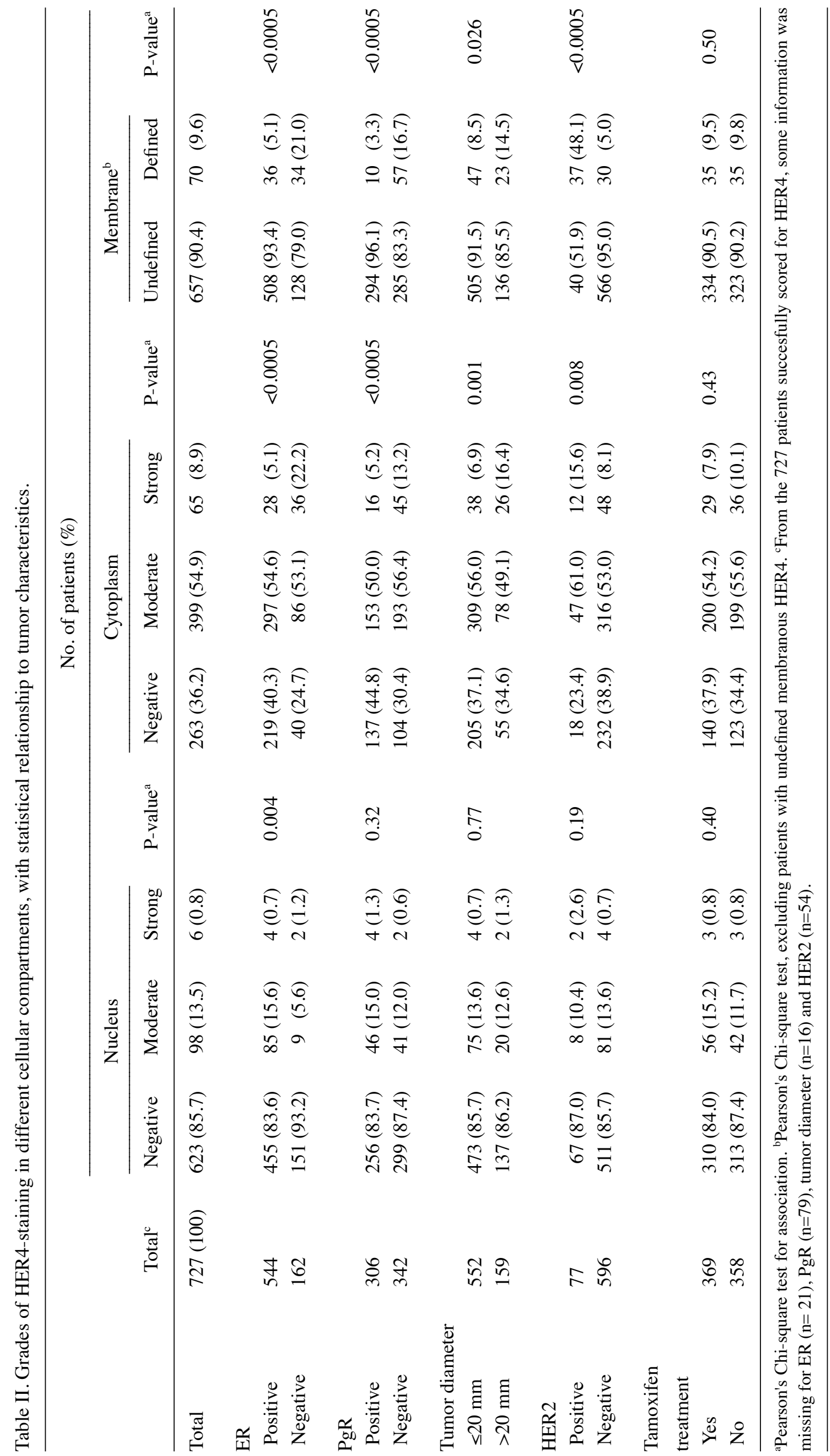


Table III. Statistical association between patients and tumor characteristics and HER4 localization.

\begin{tabular}{|c|c|c|c|c|c|}
\hline & \multicolumn{5}{|c|}{ No. of patients (\%) } \\
\hline & HER4- & $\mathrm{HER}^{\mathrm{N}}$ & HER $4^{\mathrm{C}}$ & $\mathrm{HER}_{4}{ }^{\mathrm{NC}}$ & P-value ${ }^{a}$ \\
\hline Total & $235(32.3)$ & $28(3.9)$ & $388(53.4)$ & $76(10.5)$ & \\
\hline \multicolumn{6}{|l|}{ ER } \\
\hline Positive & $196(83.4)$ & $23(82.1)$ & $259(66.8)$ & $66(86.8)$ & $<0.0005$ \\
\hline Negative & $36(15.3)$ & $4(14.3)$ & $115(29.6)$ & $7 \quad(9.2)$ & \\
\hline $\mathrm{Na}$ & $3(1.3)$ & 1 (3.6) & 14 (3.6) & $3(3.9)$ & \\
\hline \multicolumn{6}{|l|}{ PgR } \\
\hline Positive & $124(52.8)$ & $13(46.4)$ & $132(34.0)$ & $37(48.7)$ & $<0.0005$ \\
\hline Negative & $92(39.1)$ & $12(42.9)$ & $207(53.4)$ & $31(40.8)$ & \\
\hline $\mathrm{Na}$ & $19(8.1)$ & $3(10.3)$ & 49 (12.6) & $8(10.5)$ & \\
\hline \multicolumn{6}{|c|}{ Tumor diameter } \\
\hline$\leq 20 \mathrm{~mm}$ & $182(77.4)$ & $23(82.1)$ & $291(75.0)$ & $56(73.7)$ & 0.91 \\
\hline$>20 \mathrm{~mm}$ & $50(21.3)$ & $5(17.9)$ & $87(22.4)$ & $17(22.4)$ & \\
\hline $\mathrm{Na}$ & $3(1.3)$ & - & 10 & $3(3.9)$ & \\
\hline \multicolumn{6}{|l|}{ HER 2} \\
\hline Positive & $15(6.4)$ & $3(10.7)$ & $52(13.4)$ & $7 \quad(9.2)$ & 0.035 \\
\hline Negative & $208(88.5)$ & $24(85.7)$ & $303(78.1)$ & $61(80.3)$ & \\
\hline $\mathrm{Na}$ & $12(5.1)$ & 1 (3.6) & $33 \quad(8.5)$ & $8(10.5)$ & \\
\hline \multicolumn{6}{|c|}{ Tamoxifen treatment } \\
\hline Yes & $122(51.9)$ & $18(64.3)$ & $188(48.5)$ & $41(53.9)$ & 0.35 \\
\hline No & $113(48.1)$ & $10(35.7)$ & $200(51.5)$ & $35(46.1)$ & \\
\hline
\end{tabular}

${ }^{a}$ Chi-square test for association. HER4, negative; N, nuclear; C, cytoplasmic; NC, nuclear and cytoplasmic. Na, not available. For most cases, membranous HER4 was unavailable. Hence, this category is not taken into account for this analysis.

Association between HER4 protein expression and tumor characteristics. Different grades of HER4 staining were associated to tumor characteristics (Table II). Higher grades of nuclear expression (HER $4^{\mathrm{N}}$ and HER $4^{\mathrm{NC}}$ tumors) were associated to ER-positivity ( $\mathrm{P}=0.004)$ and tumors having nuclear HER4 were more often ER-positive compared to tumors without the presence of nuclear HER4 (HER4 ${ }^{\mathrm{C}}$ and HER4 tumors) $(\mathrm{P}=0.002, \mathrm{OR}=2.69,95 \% \mathrm{CI}=1.40-5.16)$. Higher grades of cytoplasmic expression (HER4 ${ }^{\mathrm{C}}$ and HER4 ${ }^{\mathrm{NC}}$ tumors) were associated with poor prognostic factors such as ER-negativity $(\mathrm{P}<0.0005), \mathrm{PgR}$-negativity $(\mathrm{P}=<0.0005)$, tumor size $>20 \mathrm{~mm}$ $(\mathrm{P}=0.001)$ and HER2-positivity $(\mathrm{P}=0.008)$. The tumors with defined membranous HER4 staining shared similar associations to poor prognostic factors (Table II).

The associations between localization of HER4 and tumor characteristics are shown in Table III where HER4 ${ }^{\mathrm{C}}$ tumors correlated negatively to $\mathrm{ER}(\mathrm{P}<0.0005, \mathrm{OR}=0.49$, 95\% $\mathrm{CI}=0.33-0.72)$ and $\mathrm{PgR}(\mathrm{P}<0.0005, \mathrm{OR}=0.54$, 95\% CI=0.39-0.74) and were more often HER2-positive compared to HER4 ${ }^{\mathrm{N}}$ and HER4 ${ }^{\mathrm{NC}}$ tumors $(\mathrm{P}=0.008, \mathrm{OR}=2.09$, 95\% CI=1.20-3.63). Finally, HER4 tumors were more often HER2-negative than HER4-positive tumors (Table III).

Prognostic relevance of HER4 protein expression. Using the Kaplan-Meier method and log-rank test, no statistical

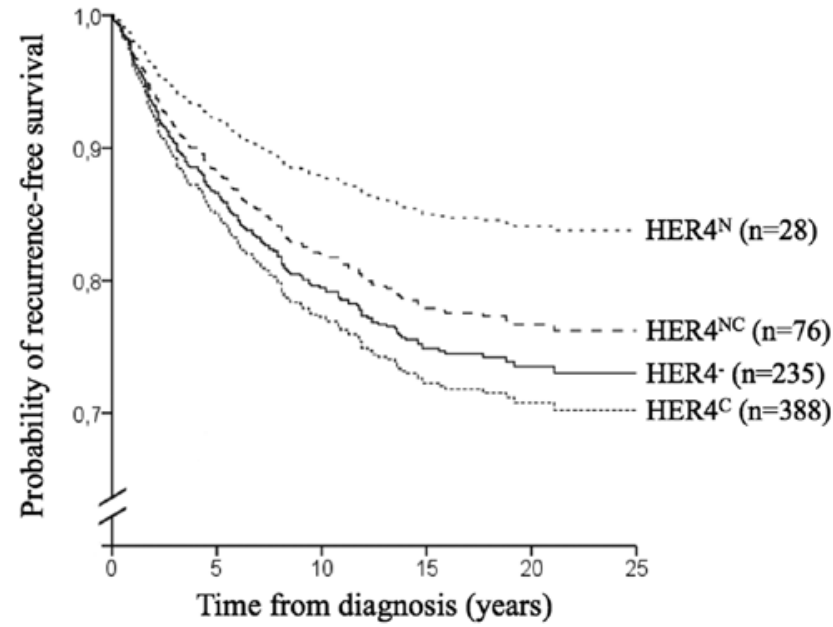

Figure 2. Survival curve obtained from Cox regression analysis of the time to recurrence differentiated by HER4 expression. Patients with a tumor showing exclusively nuclear HER4 (HER4 ${ }^{\mathrm{N}}$ ) have longer recurrence-free survival, however without statistical significance.

differences in recurrence-free survival were found in regard of HER $4^{-}$, HER $^{\mathrm{N}}{ }^{\mathrm{N}}$, HER $4^{\mathrm{C}}$ or HER $4^{\mathrm{NC}}$ expression (Fig. 2). For the 70 cases with evident membranous HER4 staining, 

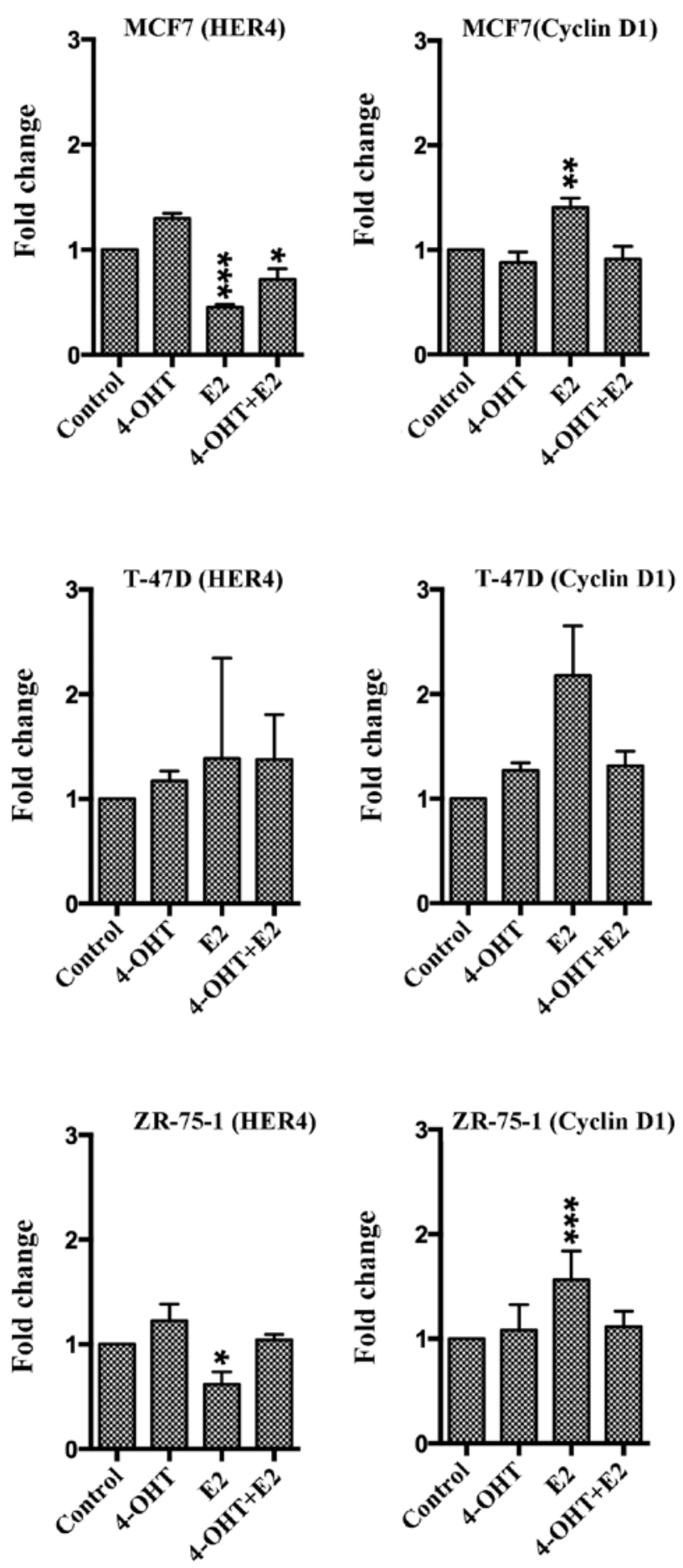

Figure 3. Results from qPCR analysis of mRNA expression of HER4 and cyclin D1 in MCF7, T-47D and ZR-75-1 cells. For all assays, two repeated experiments were performed in duplicates. Data are expressed as mean $\pm \mathrm{SD}$.

recurrence-free survival was shorter than for all cases without distinguishable membranous staining $(\mathrm{P}=0.023)$. Compared to HER4- cases, the result was no longer significant $(\mathrm{P}=0.063)$. In multivariate analysis including ER, PgR, HER2 and tumor size, there was no impact of HER4 or HER4 localization on recurrence-free survival. Multivariate test for interaction including HER4 membrane showed no additional effect of HER2 on survival.
HER4 protein expression and prediction of tamoxifen treatment. Among ER-positive patients treated with adjuvant tamoxifen there was no significant difference in recurrence-free survival in regard of HER4 expression. In order to describe tamoxifen benefit in the ER-positive patients of the present study, 65/361 (18\%) of those treated with adjuvant tamoxifen had a recurrence compared to $101 / 326$ (31\%) of those without adjuvant tamoxifen (log-rank test $\mathrm{P}<0.0005)$. When sub-analyzing ER-positive patients categorized by HER4 expression (HER4 ${ }^{-}, \mathrm{HER}^{\mathrm{N}}{ }^{\mathrm{H}}, \mathrm{HER} 4^{\mathrm{C}}$ or HER4 ${ }^{\mathrm{NC}}$ ) only HER4 patients showed significant benefit from tamoxifen treatment $(\mathrm{P}<0.0005)$ [HER $^{\mathrm{N}}(\mathrm{P}=0.98), \mathrm{HER}^{\mathrm{C}}(\mathrm{P}=0.058), \mathrm{HER}^{\mathrm{NC}}$ $(\mathrm{P}=0.40)$ and membrane HER4 $(\mathrm{P}=0.14)]$. Multivariate analysis using Cox regression, including ER, PgR, HER2 and tumor size showed no independent predictive significance of HER4 in regard of tamoxifen treatment.

Analysis of HER4 and cyclin D1 mRNA and protein expression in vitro. Three different epithelial breast cancer cell lines were used to study HER4 and cyclin D1 expression after exposure to 4-OHT, E2 and 4-OHT + E2. Cyclin D1 was used to control endocrine response. After 72-h exposure of 4-OHT, there were no significant changes in gene expression of HER4 or cyclin D1 in either cell line (Fig. 3). After exposure to E2, HER4 mRNA was decreased in MCF7 cells $(\mathrm{P}=0.0001)$ and in ZR-75-1 cells $(\mathrm{P}=0.018)$ while $\mathrm{E} 2$ exposure resulted in increased cyclin D1 mRNA levels in MCF7 cells $(\mathrm{P}=0.0066)$ and in ZR-75-1 cells $(\mathrm{P}=0.0007)$. For $\mathrm{T}-47 \mathrm{D}$ cells, there were no significant changes in HER4 or cyclin D1 gene expression. As compared to results from western blot analysis, exposure to 4-OHT resulted in a higher level of nuclear HER4 $\left(\mathrm{HER}^{\mathrm{N}}{ }^{\mathrm{N}}\right)$ in MCF7 cells, whereas cytoplasmic HER4 (HER4 ${ }^{\mathrm{C}}$ ) was decreased after E2 exposure in MCF7 cells as well as in T-47D cells (Fig. 4). E2 exposure induced cyclin D1 protein expression in all the cell lines, and the increase was blocked by co-exposure with $4-\mathrm{OHT}$.

\section{Discussion}

Receptor tyrosine kinases are important for epithelial growth in mammary tissue, and during carcinogenesis. The family member HER4 has been suggested to play a role in breast cancer growth, although opposing reports of HER4 activity has made it difficult to evaluate its clinical importance. In the present study, we assessed HER4 protein expression and its prognostic and predictive relevance in breast cancer patients $(n=912)$ randomized to adjuvant tamoxifen treatment or no adjuvant endocrine treatment (24). From the immunohistochemical staining, HER4 was detected in the cytoplasm $\left(\mathrm{HER} 4^{\mathrm{C}}\right)$, in the nucleus $\left(\mathrm{HER} 4^{\mathrm{N}}\right)$ or in both locations (HER4 ${ }^{\mathrm{NC}}$ ) of tumor cells. In addition, a small fraction of cases had a tumor with distinct HER4 membrane staining. Generally, expression of HER4 is associated to ER-positivity and may predict endocrine responsiveness because of an ER $\alpha$ co-activating role of $4 \mathrm{ICD}(11,12,23,26)$. We found a significant association between HER4 ${ }^{\mathrm{N}}$ and ER-positivity but no association to prognosis or prediction. Expression of HER4 ${ }^{\mathrm{C}}$ associated significantly to poor prognostic markers such as ER-negativity, HER2-positivity, PgR-negativity and to larger 

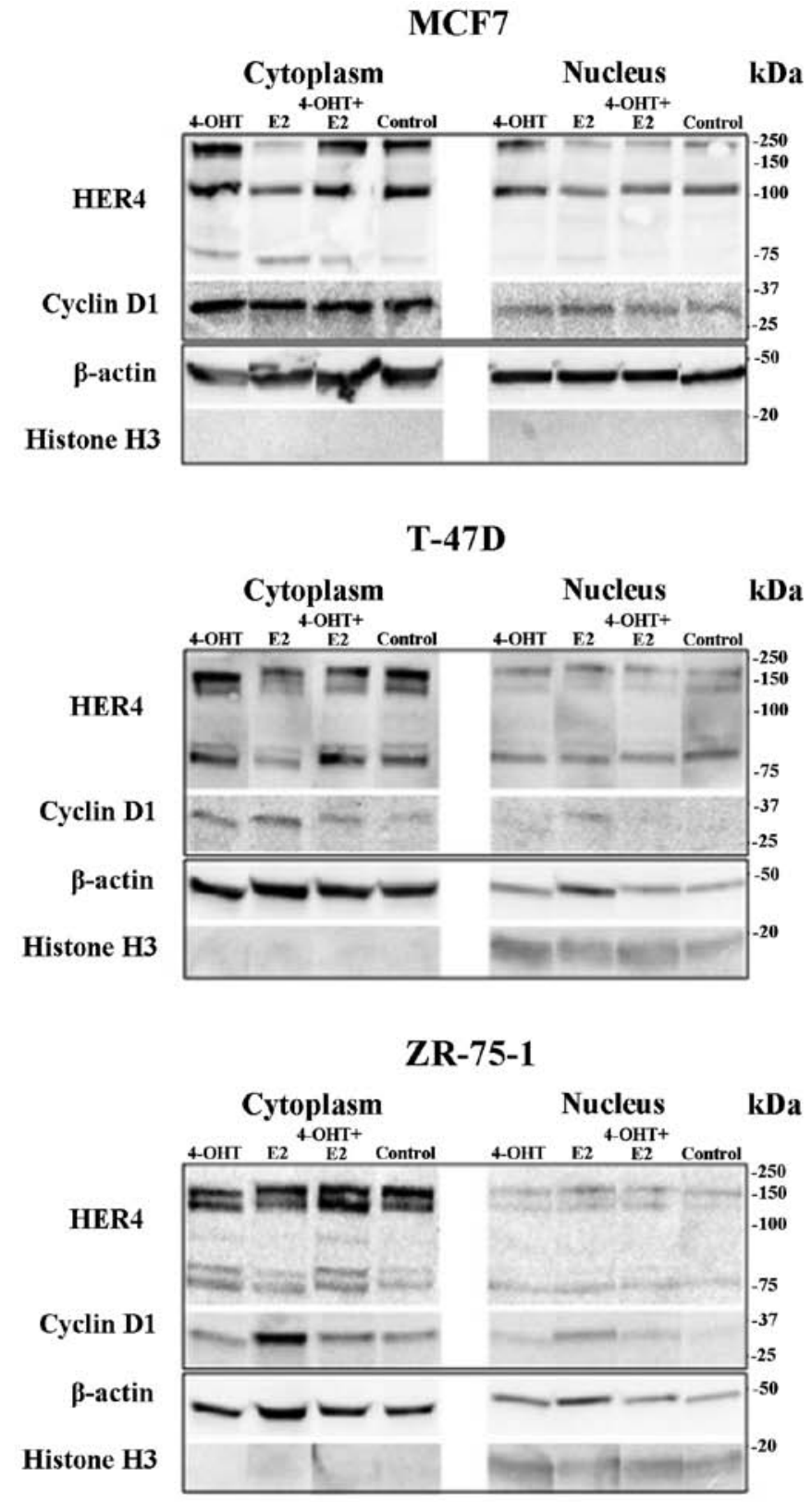

Figure 4. Western blot analysis of cytoplasmic and nuclear protein fractions in MCF7 cells, T-47D cells and ZR-75-1 cells. The anti-HER4 antibody, binding to the C-terminal intracellular part of HER4, detected up to four different bands representing different HER4 products and corresponding to the approximate sizes $180,146,80$ and $43 \mathrm{kDa}$. With the anti-cyclin D1 antibody a band with the size $36 \mathrm{kDa}$ was detected. Also, anti- $\beta$ actin $(45 \mathrm{kDa})$ antibody was used as loading control for the cytoplasmic proteins and anti-histone $\mathrm{H} 3(17 \mathrm{kDa})$ antibody for the nuclear proteins.

tumors. According to the hypothesis that HER4 ${ }^{\mathrm{C}}$ could signify increased 4ICD mitochondrial access and apoptosis, these patients should have an improved survival. In a study by Thor et al (22) cytoplasmic 4ICD correlated positively to tumor cell apoptosis as well as to ER, PgR, and improved breast cancer prognosis, which is contradictory to our findings.

The tumors with membranous HER4 may hypothetically express uncleavable JM-b-isoforms or the receptor may be inactivated or truncated. Even so, cases with membranous HER4 were shown to have a shorter recurrence-free survival than cases without. Strong cytoplasmic staining could mask membranous staining and we therefore estimated the influence of membrane HER4 in comparison to HER4- cases, and the difference in survival was no longer significant. More than half of the tumors with a defined staining of HER4 membrane were HER2-positive, raising the question whether HER4/HER2 dimerization occurs in these tumors. However, co-expression of membrane HER4 and HER2 did not affect recurrence-free survival according to our interaction test.

In a more recent breast cancer study by Fujiwara $e t$ al high intensity staining of HER 4 , or 4 ICD as they report, was observed in the nucleus, cytoplasm or in both (27). In accordance with our study, they declare an association between cytoplasmic 4ICD and HER2-positivity as well as PgR-negativity. Fujiwara et al did not find any association of nuclear 4ICD to ER but to small tumors $(\leq 20 \mathrm{~mm})$, a marker of good prognosis. In their cohort and among patients with endocrine treatment, high nuclear HER4 expression (compared to low) was significantly correlated to increased recurrence-free survival. The tamoxifen treated patients in present study showed no significant correlations between HER4 and recurrence-free survival according to our analyses.

The original hypothesis by Naresh et al stated that tamoxifen interaction to ER obstructs the binding of 4ICD to ER. This could increase 4ICD mitochondrial accumulation and following apoptosis (20). Expression of nuclear 4ICD in tumor cells could therefore involve a mechanism for tamoxifen-induced apoptosis and consequently be an advantage for tamoxifen-treated patients. HER4 absence has been associated to tamoxifen resistance (13) and is proposed to predict recurrence of ductal in situ carcinoma (28). In our results, tamoxifen was most beneficial for the HER4-negative patients, which according to Barnes et al is the most unfavorable population (28). The discordance between studies of HER4 predicting outcome from tamoxifen treatment might be caused by differential expression of HER4 isoforms. In mammary epithelia and in breast cancer, the cleavable JM-a isoform is most prominent $(15,27)$ and according to Muraoka-Cook et al CYT-2-expressing glands show increased cyclin D1 levels (17) possibly affecting tumor growth.

It is important to note that we did not use an isoformspecific anti-HER4 antibody, however, a specific anti-HER4 antibody directing the carboxy-terminal which harbours 4ICD, the principally target of interest, was used. In addition to IHC analysis of HER4 protein in breast cancer tissue, Fujiwara et al investigated what specific isoforms were expressed using qPCR (27). They found that HER4 mRNA expression comprised of both CYT-1 and CYT-2 variants and that CYT-2 was superior in terms of recurrence-free survival. Also, they found a larger proportion of HER4/CYT-1 in nuclei. Other studies claimed that overexpressed HER4/CYT-2 causes hyperplasia in mammary epithelia and CYT-2 translocate to the nucleus more easily than CYT-1 $(17,19)$. HER4 expression is clearly influenced by hormones as seen by the association to ER and in in vitro results. The levels of HER4 mRNA decreased in two out of three cell lines following E2 exposure. The cyclin D1 mRNA increased in all cell lines showing that cells are responsive to estrogenic growth stimulation. Following 4-OHT exposures, no significant changes in gene expression were detected. One explanation for the absence of tamoxifen effect could be that cellular growth in hormone-depleted 
serum may cause the same effect as estrogen blocking, thus masking the influence of tamoxifen. Other researchers have found that HER4 increases in response to endocrine treatment (such as 4-OHT and fulvestrant) and decreases in response to E2 (29,30). HER4 is transcriptionally repressed by estrogen stimulation (30), explaining why tamoxifen exposure results in increased HER4. The main reason for the in vitro experiments was to investigate whether 4ICD locates predominantly to nucleus or cytoplasm following exposure to E2 and 4-OHT. In the western blot results, all three breast cancer cell lines revealed an $80 \mathrm{kDa}$ band corresponding to the size of the cleaved carboxyterminal product 4ICD. When analyzing contents in isolated cellular compartments, both $\mathrm{HER} 4^{\mathrm{C}}$ and HER $4^{\mathrm{N}}$ decreased after E2 exposure. In line with the qPCR results, cyclin D1 protein expression increased. There was, however, no visual difference in nuclear or cytoplasmic protein fractions.

In conclusion, the present study showed no significance of HER4 expression in breast cancer survival, however, an association to biological markers related to endocrine response was evident. Using more sophisticated techniques, future studies may reveal whether HER4 expression add prognostic or predictive relevance for breast cancer outcome.

\section{Acknowledgements}

This study was supported by grants from Nyckelfonden, Örebro University Hospital, Sweden and Lions Cancer Research Foundation, Region Uppsala - Örebro, Sweden and the Stockholm Cancer Society, Sweden. We thank Christine Pentz (MSc) for help with cell culturing and Hanna Arnesson (ML) for assistance with western blot analyses.

\section{References}

1. Ferlay J, Shin HR, Bray F, Forman D, Mathers C and Parkin DM Estimates of worldwide burden of cancer in 2008: GLOBOCAN 2008. Int J Cancer 127: 2893-2917, 2010.

2. Burstein HJ, Temin S, Anderson H, Buchholz TA, Davidson NE, Gelmon KE, Giordano SH, Hudis CA, Rowden D, Solky AJ, et al: Adjuvant endocrine therapy for women with hormone receptorpositive breast cancer: American Society of Clinical Oncology clinical practice guideline focused update. J Clin Oncol 32: 2255-2269, 2014

3. Lumachi F, Brunello A, Maruzzo M, Basso U and Basso SM: Treatment of estrogen receptor-positive Breast Cancer. Curr Med Chem 20: 596-604. 2013.

4. Davies C, Godwin J, Gray R, Clarke M, Cutter D, Darby S, McGale P, Pan HC, Taylor C, Wang YC, et al; Early Breast Cancer Trialists' Collaborative Group (EBCTCG): Relevance of breast cancer hormone receptors and other factors to the efficacy of adjuvant tamoxifen: Patient-level meta-analysis of randomised trials. Lancet 378: 771-784, 2011.

5. Kilker RL, Hartl MW, Rutherford TM and Planas-Silva MD: Cyclin D1 expression is dependent on estrogen receptor function in tamoxifen-resistant breast cancer cells. J Steroid Biochem Mol Biol 92: 63-71, 2004.

6. Wegman P, Elingarami S, Carstensen J, Stål O, Nordenskjöld B and Wingren S: Genetic variants of CYP3A5, CYP2D6, SULT1A1, UGT2B15 and tamoxifen response in postmenopausal patients with breast cancer. Breast Cancer Res 9: R7, 2007.

7. Ghayad SE, Vendrell JA, Ben Larbi S, Dumontet C, Bieche I and Cohen PA: Endocrine resistance associated with activated ErbB system in breast cancer cells is reversed by inhibiting MAPK or PI3K/Akt signaling pathways. Int J Cancer 126: 545-562, 2010.

8. Lindberg K, Helguero LA, Omoto Y, Gustafsson JA and Haldosén LA: Estrogen receptor $\beta$ represses Akt signaling in breast cancer cells via downregulation of HER2/HER3 and upregulation of PTEN: Implications for tamoxifen sensitivity. Breast Cancer Res 13: R43, 2011.
9. Normanno N, Di Maio M, De Maio E, De Luca A, de Matteis A, Giordano A and Perrone F; NCI-Naple Breast Cancer Group: Mechanisms of endocrine resistance and novel therapeutic strategies in breast cancer. Endocr Relat Cancer 12: 721-747, 2005.

10. Ring A and Dowsett M: Mechanisms of tamoxifen resistance. Endocr Relat Cancer 11: 643-658, 2004.

11. Knowlden JM, Gee JM, Seery LT, Farrow L, Gullick WJ, Ellis IO, Blamey RW, Robertson JF and Nicholson RI: c-erbB3 and c-erbB4 expression is a feature of the endocrine responsive phenotype in clinical breast cancer. Oncogene 17: 1949-1957, 1998.

12. Fujiwara S, Ibusuki M, Yamamoto S, Yamamoto $Y$ and Iwase H: Association of ErbB1-4 expression in invasive breast cancer with clinicopathological characteristics and prognosis. Breast Cancer 21: 472-481, 2012

13. Guler G, Iliopoulos D, Guler N, Himmetoglu C, Hayran M and Huebner K: Wwox and Ap2gamma expression levels predict tamoxifen response. Clin Cancer Res 13: 6115-6121, 2007.

14. Kainulainen V, Sundvall M, Määttä JA, Santiestevan E, Klagsbrun M and Elenius K: A natural ErbB4 isoform that does not activate phosphoinositide 3-kinase mediates proliferation but not survival or chemotaxis. J Biol Chem 275: 8641-8649, 2000.

15. Elenius K, Corfas G, Paul S, Choi CJ, Rio C, Plowman GD and Klagsbrun M: A novel juxtamembrane domain isoform of HER4/ErbB4. Isoform-specific tissue distribution and differential processing in response to phorbol ester. J Biol Chem 272: 26761-26768, 1997.

16. Elenius K, Choi CJ, Paul S, Santiestevan E, Nishi E and Klagsbrun M: Characterization of a naturally occurring ErbB4 isoform that does not bind or activate phosphatidyl inositol 3-kinase. Oncogene 18: 2607-2615, 1999.

17. Muraoka-Cook RS, Sandahl MA, Strunk KE, Miraglia LC, Husted C, Hunter DM, Elenius K, Chodosh LA and Earp HS III: ErbB4 splice variants Cyt1 and Cyt 2 differ by 16 amino acids and exert opposing effects on the mammary epithelium in vivo. Mol Cell Biol 29: 4935-4948, 2009.

18. Sundvall M, Veikkolainen V, Kurppa K, Salah Z, Tvorogov D, van Zoelen EJ, Aqeilan R and Elenius K: Cell death or survival promoted by alternative isoforms of ErbB4. Mol Biol Cell 21: 4275-4286, 2010.

19. Sundvall M, Peri L, Määttä JA, Tvorogov D, Paatero I, Savisalo M, Silvennoinen O, Yarden Y and Elenius K: Differential nuclear localization and kinase activity of alternative ErbB4 intracellular domains. Oncogene 26: 6905-6914, 2007.

20. Naresh A, Thor AD, Edgerton SM, Torkko KC, Kumar R and Jones FE: The HER4/4ICD estrogen receptor coactivator and $\mathrm{BH} 3$-only protein is an effector of tamoxifen-induced apoptosis. Cancer Res 68: 6387-6395, 2008.

21. Naresh A, Long W, Vidal GA, Wimley WC, Marrero L, Sartor CI, Tovey S, Cooke TG, Bartlett JM and Jones FE: The ERBB4/HER4 intracellular domain 4ICD is a BH3-only protein promoting apoptosis of breast cancer cells. Cancer Res 66: 6412-6420, 2006.

22. Thor AD, Edgerton SM and Jones FE: Subcellular localization of the HER4 intracellular domain, 4ICD, identifies distinct prognostic outcomes for breast cancer patients. Am J Pathol 175: 1802-1809, 2009.

23. Rokicki J, Das PM, Giltnane JM, Wansbury O, Rimm DL, Howard BA and Jones FE: The ERalpha coactivator, HER4/4ICD, regulates progesterone receptor expression in normal and malignant breast epithelium. Mol Cancer 9: 150, 2010.

24. Rutqvist LE and Johansson H: Long-term follow-up of the randomized Stockholm trial on adjuvant tamoxifen among postmenopausal patients with early stage breast cancer. Acta Oncol 46: 133-145, 2007.

25. Subik K, Lee JF, Baxter L, Strzepek T, Costello D, Crowley P, Xing L, Hung MC, Bonfiglio T, Hicks DG, et al: The expression patterns of ER, PR, HER2, CK5/6, EGFR, Ki-67 and AR by immunohistochemical analysis in breast cancer cell lines. Breast Cancer (Auckl) 4: 35-41, 2010.

26. Han W and Jones FE: HER4 selectively coregulates estrogen stimulated genes associated with breast tumor cell proliferation. Biochem Biophys Res Commun 443: 458-463, 2014.

27. Fujiwara S, Hung M, Yamamoto-Ibusuk CM, Yamamoto $Y$, Yamamoto S, Tomiguchi M, Takeshita T, Hayashi M, Sueta A and Iwase H: The localization of HER4 intracellular domain and expression of its alternately-spliced isoforms have prognostic significance in $\mathrm{ER}^{+} \mathrm{HER} 2^{-}$breast cancer. Oncotarget 5: 3919-3930, 2014 
28. Barnes NL, Khavari S, Boland GP, Cramer A, Knox WF and Bundred NJ: Absence of HER4 expression predicts recurrence of ductal carcinoma in situ of the breast. Clin Cancer Res 11: 2163-2168, 2005.

29. Hutcheson IR, Goddard L, Barrow D, McClelland RA, Francies HE, Knowlden JM, Nicholson RI and Gee JM: Fulvestrant-induced expression of ErbB3 and ErbB4 receptors sensitizes oestrogen receptor-positive breast cancer cells to heregulin $\beta 1$. Breast Cancer Res 13: R29, 2011.

30. Revillion F, Pawlowski V, Lhotellier V, Louchez MM and Peyrat JP: mRNA expression of the type I growth factor receptors in the human breast cancer cells MCF-7: Regulation by estradiol and tamoxifen. Anticancer Res 23B: 1455-1460, 2003. 